\title{
Charles-Joseph de Ligne, Coup d'œil sur Belœil. Écrits sur les jardins et l'urbanisme
}

\section{Maria Immacolata Spagna}

\section{(2) OpenEdition}

\section{Edizione digitale}

URL: http://journals.openedition.org/studifrancesi/30363

DOI: 10.4000/studifrancesi.30363

ISSN: 2421-5856

\section{Editore}

Rosenberg \& Sellier

\section{Edizione cartacea}

Data di pubblicazione: 1 avril 2006

Paginazione: 162-163

ISSN: 0039-2944

\section{Notizia bibliografica digitale}

Maria Immacolata Spagna, «Charles-Joseph de Ligne, Coup d"œil sur Belœil. Écrits sur les jardins et l'urbanisme», Studi Francesi [Online], 148 (XLX | I) | 2006, online dal 30 novembre 2015, consultato il 18 avril 2021. URL: http://journals.openedition.org/studifrancesi/30363 ; DOI: https://doi.org/10.4000/ studifrancesi.30363 


\title{
Charles-Joseph de Ligne, Coup d'œil sur Belœil. Écrits sur les jardins et l'urbanisme
}

\author{
Maria Immacolata Spagna
}

\section{NOTIZIA}

CHARLES-JOSEPH DE LIGNE, Coup d'œil sur Belœil. Écrits sur les jardins et l'urbanisme.

Etablissemente du texte, introduction et notes par Jeroom VERCRUYSSE et Basil GUY. Avec le concours de Marianne Delvaulx et Pierre Mouriau de Meulenacker. Paris, Honoré Champion, 2004, («L'Âge des Lumières», n. 25), pp. 622.

1 La presente edizione critica raccoglie tutti i testi in cui il principe de Ligne affronta la questione dell'allestimento dei giardini e quella dell'urbanesimo nel XVIII secolo in Europa. In particolare, riproduce integralmente le quattro versioni esistenti del Coup d' œil sur Belœil, l'opera più famosa di de Ligne sull'argomento: la prima è quella manoscritta, inedita fino a questo momento (pp. 109-135); la seconda coincide con la prima pubblicazione, quella del 1781 (pp. 137-220); la terza corrisponde alla seconda edizione che risale al 1786 (pp. 222-322); la quarta, infine, riprende l'ultima pubblicazione, quella del 1795 , sensibilmente modificata rispetto alle precedenti (pp. 324-475). Messe a confronto, tali versioni successive, che coprono un intervallo temporale superiore ad un quarto di secolo, consentono al lettore di cogliere l'evoluzione delle idee e dei gusti dell'autore e, nel contempo, di approfondire un periodo, come la fine del Settecento, denso di sconvolgimenti economici, politici e filosofici.

Gli editori del presente volume, al fine di proporre un quadro completo degli scritti del principe sui giardini e l'urbanesimo, hanno deciso di pubblicare, oltre al Coup d'œil sur Beloeil, gli altri testi, in alcuni casi anche brevissimi, dedicati a tale tema, la maggior parte dei quali apparsi nei Mélanges. In ordine di presentazione, l'edizione critica 
raccoglie: Mémoire sur Paris (pp. 479-490) e Mémoire sur Vienne (pp. 491-494), in cui il principe suggerisce per le due capitali europee di apportare alcune modifiche ambientali, ispirate dal suo desiderio di adattare il 'milieu' a vantaggio del benessere generale; Vers que l'on suppose avoir été ajoutés au poème des Jardins (pp. 495-496), trentadue versi in cui de Ligne sottolinea la necessità di potersi rinfrescare nelle acque dei giardini, necessità trascurata dall'abate Delille nei Jardins. Questa edizione critica presenta di de Ligne anche il testo Mon refuge, ou satire sur les abus des jardins modernes (pp. 497-531), un'evocazione dei suoi 'ermitages' dei paesaggi del Kahlenberg e del Leopoldsberg; otto versi, dal titolo Dans le livre de Schonhof où écrivent ceux qui y vont (p. 533), dedicati al conte Jean Rodolphe Czemin von Chudenitz, proprietario di Schönhof; un elogio, À Sidonienwald, où le comte Chotek a créé tout ce que je dis ici dans ces vers (pp. 533-534), alle creazioni a Sidonienwald, compiute dall'amico, nonché parente, il conte Rodolphe Chotek; Voyage pittoresque (pp. 535-544), in cui de Ligne rivolge ai poeti e ai disegnatori di Vienna una serie di consigli in materia di urbanesimo; Au prince Poutiatine, sur son jardin charmant et extraordinare(pp. 545-546), che consiste in alcuni apprezzamenti sul giardino di Dresda del principe Nicolas Avramovitch Poutiatin. In Les délices de Vienne et de ses environs ou les quatre saisons (pp. 547-554), il principe rileva con qualche ironia i cambiamenti della vita quotidiana viennese. In Mémoire (pp. 555-557), la seconda versione di Mémoire sur Vienne, infine, egli ripropone le idee già presentate qualche anno prima.

In tutti i testi raccolti in questo volume si respira la forte passione per il giardinaggio, che per de Ligne diventa un'arte carica non solo di bellezza ma anche di significato morale. Le sue pagine hanno per fondamento l'essere umano, i suoi bisogni e i suoi valori.

I numerosi viaggi e le abbondanti letture hanno aiutato il principe in questo percorso e hanno determinato le molteplici revisioni e correzioni apportate ai testi. La conoscenza diretta dei vari giardini inglesi, russi, italiani e polacchi, oltre che francesi, permette a de Ligne di affrontare con precisione e ricchezza di dati il tema dell'urbanesimo. Il testo è impreziosito dal supporto delle citazioni di Virgilio, Orazio, Ovidio, Rousseau e Voltaire. 